\title{
PATERNALISM TOWARDS CHILDREN
}

\author{
Kalle Grill
}

\begin{abstract}
Debates on the nature and justifiability of paternalism typically focus only on adults, sometimes presuming without argument that paternalism towards children is a non-issue or obviously justified. Debates on the moral and political status of children, in turn, rarely connect with the rich literature on paternalism. This chapter attempts to bridge this gap by exploring how issues that arise in the general debate on paternalism are relevant also for the benevolent interference with children. I survey and discuss various views and argue for my own: that paternalism towards children is in most respects like paternalism towards adults and stands in the same need of justification, though such justification is more often forthcoming both because children are typically less prudent than adults and so benefit more from interference, and because, in some respects, interference is less harmful to them.
\end{abstract}

\section{Introduction}

Discussions of paternalism in contemporary moral and political philosophy revolve around a series of related questions: To what extent may people harm themselves, risk harm to themselves, or simply fail to optimally promote their own interests? When should others interfere with potentially self-harming or sub-optimal behavior? What role should a person's will or preference, and her own view of her good, play in answering these questions? Children appear in the paternalism debate mainly as archetypical targets of justified benevolent interference. Paternalism is frequently described as treating adults as if they were children, with the assumption that children have no right to self-direction that could conflict with their being forced against their will (e.g. De Marneffe 2006; Quong 2010: 73; Tsai 2014).

At the same time, discussions of the moral and political status of children only rarely connect with the finer details of the paternalism debate (but see Aviram 1991). In this chapter, I describe the general contours of the philosophical debate on paternalism and consider how the issues raised in this debate relate to children and childhood in particular. While surveying various views, I also argue for my own view: children are like adults in some ways, importantly by having a will that warrants some measure of respect, but unlike adults in other ways, such as being less prudent and less vulnerable to the harms of paternalistic interference; there is no blanket justification for paternalism towards children, but many particular instances are justified.

\section{Paternalism and its components}

Contemporary philosophical debate on paternalism typically takes as its starting point John Stuart Mill's Liberty principle, as formulated in On Liberty: 
[T] he sole end for which mankind are warranted, individually or collectively, in interfering with the liberty of action of any of their number, is self-protection. [T] he only purpose for which power can be rightfully exercised over any member of a civilized community, against his will, is to prevent harm to others. His own good, either physical or moral, is not a sufficient warrant. (Mill 1859/1869: chapter 1, 9th paragraph) [p.124]

Paternalism can usefully be understood as that against which Mill's Liberty principle is directed. ${ }^{1}$ On this reading, the debate is about what exactly should be understood by interference with someone's liberty or the exercise of power over someone, what should be understood by something being against someone's will, and what should be understood by something being warranted by someone's good. These questions can be answered either from a normative perspective, aiming to identify paternalism as something morally problematic, or from a more conceptual perspective, where the moral status of paternalism is an open question. Without settling any normative or conceptual disagreements, we may simply label the three components of paternalism the interference component, the will component and the good component. Paternalism involves some sort of interference, some sort of disregard for will, and some sort of benevolent reason. In the rest of this chapter, I discuss these components and how they relate to children, with one section devoted to each component. After discussing the will component I pause to consider the concept of soft paternalism, and in relation to discussing the good component, I particularly address future autonomy as a good.

\section{Paternalistic interference with a child}

Interference is what makes paternalism at least potentially morally problematic. It is quite controversial, however, what sort of things can be paternalistically interfered with. Mill's formulation "interfering with the liberty of action" sounds rather narrowly concerned with action, while his formulation "exercise of power over" sounds quite broad. Most authors nowadays accept a broader understanding such that it can be paternalism not just to prevent a person from acting, but also to e.g. withhold information from someone or to give medical treatment to someone who is unconscious (e.g. Gert \& Culver 1976).

A particular ambiguity concerns the distinction between what is self-regarding and what is other-regarding. Liberals are concerned to distinguish a sphere of each person's life that does not directly affect others, or affects others only "with their free, voluntary, and undeceived consent and participation" (Mill 1859/1869: I.12), and which therefore should be protected from all interference. Paternalism has been closely associated with this project, to the point of claiming that paternalism can only be interference with something self-regarding (e.g. Gray 1983: 90; Feinberg 1986: 22). This is arguably a mistake, since we can interfere with a person for her good and against her will also when she is interacting with others, or even harming them. That I harm or risk harm to others does not, or not obviously, make it less problematic to invasively promote my interests. 
The issue of self-regarding vs. other-regarding is especially relevant for children, who, because of their dependence on others, have very small or non-existent self-regarding spheres. Almost everything a small child does will affect her parents or guardians directly and substantially. Furthermore, parents do not consent to being so affected. They may have taken on their roles voluntarily, but this does not, I propose, entail blanket consent to their children's particular behavior. Therefore, if paternalism were limited to interference with a self-regarding sphere, much interference with children would not be paternalism. As I just argued, however, we should not think that paternalism is so limited, and intuitions to the effect that children can be targets of paternalism give further support to this position.

Another controversial issue is what sorts of actions count as interfering in the context of paternalism. Traditionally, this has included only compulsion, deception, coercion, and making options more costly by e.g. taxing them. In the conceptual debate, these action types have sometimes been operationalized in terms of diminishment of choice (e.g. Archard 1990) or substitution of judgment (e.g. Dworkin 1983). Mill is very clear that his Liberty principle does not [p. 125] prevent benevolent argument and persuasion, even when these are unwanted. Recently, this traditional view has been challenged by the introduction of the term "libertarian paternalism" and the ensuing debate on so called nudging. In brief, nudging is influencing choice via design of the choice context rather than by any changes to the content of alternatives, and libertarian paternalism is the position that nudging should be used benevolently but that any means that significantly affect incentives should not. According to its original proponents, libertarian paternalism is paternalism because "it attempts to influence the choices of affected parties in a way that will make choosers better off." (Sunstein and Thaler 2003: 1162) Along similar lines it has been argued specifically that even rational persuasion can be paternalistic (Tsai 2014). Some types of nudging seem manipulative because they bypass the targets rational agency, and may therefore count as paternalism even on more traditional accounts (e.g. Scoccia 2013). Other nudges, however, do not seem manipulative at all, since they simply activate a person's rational agency (Hanna 2015).

With nudging, as well as with paternalism more generally, it is not easy to decide which means are interfering and which are not. Linguistic intuitions about what cases "feel" paternalistic, rather common in the conceptual debate, may not align with considered judgments about which cases are morally problematic. Leaving this demarcation problem to one side, we can note that children are often the target of compulsion, coercion, manipulation, nudging and unwanted rational persuasion, though rational persuasion of course requires that the child has at least rudimentary language skills.

Many things that are typically important to adults are not important to many children. Indeed, younger children may not even be physically able to do some things that adults value doing. Examples include marrying, running for office, and hiking in the wild. It may therefore seem that preventing these children from doing these things cannot be coercive or cannot be paternalism. This is a mistake because it is not generally the case that whether or not some form of prevention is interfering or paternalistic depends on whether or not the targeted person cares about the option that is being closed or burdened, or even whether or not she is able to utilize the option. My lack of interest in smoking does not make it innocuous to prevent me from smoking 
for my own good. Depending on one's theory of liberty, my (let us presume) inability to hike in the wild may or may not entail that my liberty cannot be limited by additional, redundant, preventive measures. However, such prevention would surely be obnoxious. Inability cannot justify prevention. What might justify prevention is if someone $i$ s able to do something, but is either unable to make a sufficiently competent choice to do it - paternalism's will component paternalism - or is at risk of harming herself by doing it - paternalism's good component.

\section{Against a child's will}

Benevolent interference with a person is not paternalism if she consents to it. At least this is so if the consent is sufficiently free, informed and rational. I will leave to one side the intricate issue of how to categorize less clear-cut cases, when there is neither clear consent nor clear protest some hold that there is paternalism only if the interference is actually against a person's will (VanDeVeer 1986; Arneson 2015), while others hold that it is sufficient that the interference is undertaken independently of the person's will (Gert and Culver 1976; Pope 2004). I will focus instead on what it means to will something, when we do, and to what extent children are different from adults in this regard.

Traditionally, it has been taken for granted that adults have and act on rather settled preferences, which are independent of the choice situations we face, and that this warrants respect for our will. Joel Feinberg, arguably the most important proponent of Millian anti-paternalism in [p. 126] the 20th century, emphasizes the many ways in which voluntary choice can be compromised by controlling influences and temporary distortions, but presumes, with Mill, that adults have settled preferences, even if we sometimes fail to act on them (1986: 115). In contrast, children are traditionally presumed to lack settled preferences. Mill lists children together with people who are "delirious" or "in some state of excitement or absorption incompatible with the full use of the reflecting faculty" as exceptions that are not protected by his Liberty principle (Mill 1859/1869: V:5). Tamar Schapiro defends this traditional view in a Kantian context by pointing to a child's lack of "a unified regulative perspective which counts as the expression of her will" (1999: 729).

These traditional assumptions can be challenged in two main ways. One is to focus on children's abilities. Amy Mullin argues that children under ten have at least some degree of autonomy in some areas of their lives since they have sufficient volitional stability, self-control over their commitments and goals, understanding of the way their actions promote or thwart the fulfillment of those goals, and confidence that they can reach those goals via those actions (2014: 415-16). Sam Frankel argues, based on interviews with children, that children aged 9-11 navigate a moral universe quite similar to that of adults, fully aware of power relations and the enforcement of moral norms, and so should be considered moral agents (Frankel 2012). David Archard argues convincingly that many children possess all three elements commonly required for autonomy rationality, maturity and independence (Archard 2015: 88-92). Archard also cites empirical studies, including Oliva Stevens (1982), that indicate that children as young as seven are quite able to process information and use it intelligently and independently, and that by age eleven, children typically possess a political vocabulary as good as that of many adults, as well as a 
framework of ideas that would enable them to make informed political judgments, and so to vote in political elections (Archard 2015: 142-3). If children can deliberate about morality and politics, they can surely also deliberate about everyday matters such as whether to have or skip family dinner. While Feinberg's antipaternalism only applies to adults, he states in his explicit treatment of children that many or most "autonomy rights" (i.e. liberties) a person will have as an adult are acquired already at age "ten or twelve" (1980/1994: 95; 1986: 326). There are, in summary, many reasons to hold that rather young children are quite able to form and capably act on preferences.

The other way to challenge the idea that children and adults differ significantly in terms of rationality, autonomy or settled preferences is to look closer at adults. Advances in behavioral psychology over the past several decades have shown that it is no easy matter to even determine what an adult person wants or prefers (e.g. Thaler and Sunstein 2008). Because we are often weak-willed and suggestible we may not act on or express ourselves according to our own preferences. Because we are often uninformed and irrational, and because we often lack settled preferences that are independent of our immediate context, our preferences are incoherent over times and contexts. This all means that it is far from clear what it means to respect an adult person's will, and so what it means for an action to be against her will (Grill 2015). It is therefore far from clear that most adults have the "unified regulative perspective" that Schapiro, with Kant, presumes that we have. To the extent that we perceive ourselves to have such a perspective, this may be self-delusion.

Behavioral findings have been widely invoked to justify various involvements in people's lives designed to help them choose more rationally, i.e. more in accordance with their own longterm goals. Sarah Conly goes as far as to claim that, because respect for autonomy is based on a presumption of rationality, "our belief that autonomous actions should not be interfered with was based on a mistake" (2012, p. 192). In other words, Conly argues that we should treat adults more like we treat children, because adults are not much more rational. [p. 127]

However, an alternative reaction is to foreground Mill's invocations of the value of individuality and self-creation, which are not necessarily dependent on prudent choice. Mill argues that these values thrive when we are allowed to make our own decisions. This may be true even if our deliberative capacities are less exalted than we would like to believe, or less exalted than we had good reason to believe before behavioral psychology showed us otherwise. Instead of concluding from behavioral psychology that we have surprisingly meager reasons to respect autonomy, we might conclude that what we have good reason to respect is surprisingly meager. If we should respect the will of adults, even if it is irrational and incoherent, then it is more difficult to argue that we should not respect the will of children. Degrees are important of course, but the strong division of people into adults and children would be more plausible if adults typically reached some sort of maximal capacity for rational choice, or at least some significant threshold. With members of both groups typically scoring rather low and far from maximal capacity, the case for treating members according to what group they belong to is arguably rather weak.

Other abilities or properties have been invoked to argue that children's will is insufficiently informed and rational to warrant the sort of respect we typically give adults. Geoffrey Scarre argues that children lack the ability to make systematic plans for their own future and that this 
renders them as a class irrational, to the extent that it justifies a general paternalistic regime (Scarre 1980). Norvin Richards argues more recently that though children have a will that deserves some respect, they lack, at least in many cases, the self-awareness necessary for identifying as a coherent person over time, thinking of their choices in terms of self-creation (Richards 2010: 127-134). Both proposals may point to something less ambitious and so more realistic than Schapiro's unified regulative perspective, while still excluding children from consideration. However, it is not obvious that a person's lack of the ability for self-aware selfcreation, or for forming systematic life plans, should undermine respect for her will. Imagine an adult person who is both inherently unsystematic in his life plans and also lacks the awareness that he is continuously creating himself via his choices. Perhaps this person is extremely unreflective and spontaneous, absorbed by one or other interest at any given time, changing between them unsystematically. Perhaps such a person would have some sort of medical condition, a personality disorder or Autism Spectrum Disorder. However, I propose that such divergence from normalcy would not justify disregarding this person's will. Therefore, similar divergences do not undermine respect for children.

I propose, in conclusion, that children have preferences and a will and that at least from the age of seven this will is not, for most children, very different from that of a normal adult in its basic functioning. However, what children will, or want, may often be quite myopic. Young children are often quite spontaneous, oblivious to what will be important to them in the next moment, much less the next year. Many adolescents are easily overwhelmed by strong impulses and feelings, which they may be experiencing for the first time. Adolescents also typically lack a sense of proportion and may have a strongly inflated or deflated view of themselves. This all means that children may on average be less prudent than adults, which means that they will more often make choices that are suboptimal or even harmful from a long-term prudential perspective. This in turn may give us stronger reason to interfere with them against their will and for their good. When we do so, however, we treat them paternalistically, just as we would if we did the same thing, for the same reasons, towards an adult.

\section{Voluntariness and Children: Hard and soft paternalism}

Paternalism is interference with a person for her good and against her will. However, Feinberg proposes that benevolent interference with a choice that is substantially nonvoluntary should [p. 128] count as soft paternalism and is morally permissible. This is, Feinberg explains, because such choices are not genuinely ours, they do not originate from our will (even when we in principle have one). Nonvoluntary choices are "as alien to [us] as the choices of someone else" (1986: 12). Therefore, Feinberg reasons, it is really only hard paternalism, i.e. benevolent interference with fully voluntary choices, that is proper paternalism. Feinberg's view has become standard in the philosophical paternalism debate. In more applied contexts it is often presumed without argument that soft paternalism is permissible.

It is sometimes claimed that paternalism towards children is always soft paternalism and therefore justified. However, while Feinberg only awards absolute protection from hard paternalism to competent adults, he never argues that all paternalism towards children is soft. 
Moreover, his comprehensive treatment of voluntariness does not provide much basis for such an argument. Feinberg distinguishes five families of voluntariness-reducing factors (1986: 115). The first is competence understood as a basic requirement for voluntary choice. Feinberg explicitly states that this excludes infants, but clearly does not mean to exclude non-infant children. The remaining four are coercion and duress, subtle manipulation, ignorance and mistake, and temporarily distorting circumstances. The first two are perhaps circumstances that befall children more often, but this is partly because paternalism towards them is widely considered unproblematic. It seems ignorance is the only factor on which children generally do worse than adults for less contingent reasons. Ignorance is also the basis on which Feinberg argues elsewhere in his book that children often cannot give valid consent (1986: 325-332).

It is not clear, however, that children typically make less informed choices than adults, or would do so if allowed to. Certainly young children are typically more ignorant than adults in the sense that they have a smaller set of true beliefs (though many high school students may have an advantage over those adults whose information is outdated and fragmented). However, children also typically make choices that are more local and involve less complex information. Children in nursery choose what to play and with whom, while adults at work may choose what stock to invest in, what diagnoses to give a patient, or how to plan a new course in the philosophy of childhood and children. There are certainly some choices that young children could potentially make and for which they are not well equipped. Feinberg argues that a 3-year-old is not sufficiently informed about financial matters to voluntarily invest in real estate (1986: 325). This sounds right. However, Feinberg goes on to argue that the same goes for a 15-year-old, because "he cannot yet have a full visceral appreciation of the significance of an irrevocable transaction for his future interest over the course of a lifetime." (Ibid.) This seems an impossibly high standard, one that no person, child or adult, could live up to.

It should be recognized that adults generally have a greater appreciation of the long-term consequences of their choices, as well as more goal-oriented behavior. This probably depends both on their greater mental capacity and on their greater life experience. Adolescents in particular seek novel experiences and take greater risk. There are neurological explanations for these behaviors, observed in many species, and presumed to aid the development of greater independence (Casey et. al. 2008). However, it is not clear that the advantage a 20-year-old has over a 15-year-old, in these regards, is any greater than what a 35-year-old has over a 20-yearold, or what a well-educated and reflective adult has over a poorly educated and unreflective adult. More importantly, it is not clear to what extent one must have a good appreciation of longterm consequences in order not to be ignorant in a way that makes one's choice non-voluntary. If the self-regarding choices of people with poor appreciation of their own future wellbeing is nonvoluntary, then the other-regarding choices of people with poor appreciation of other's people's wellbeing must also be non-voluntary. But is not clear that we are any more justified in interfering with the other-regarding choices of those lacking in [p. 129] empathy, except to the extent to which they actually harm or risk harming others. Likewise, it is not clear that we are any more justified in interfering with those lacking in long-term prudence, except to the extent to which they actually harm or risk harming themselves. Harm and risk, however, is an aspect of the good component of paternalism, not the will component. 
The last voluntariness-reducing factor is temporarily distorting circumstances. These can befall people of all ages. In fact, the kinds of circumstances that Feinberg lists arguably affect adults more than children. They include fatigue, neurosis, being under the influence of mindnumbing drugs, and extreme time pressure. This indicates that it may be the choices of adults that are more often substantially nonvoluntary and so open to soft paternalist interference.

For both distorting circumstances and controlling influences from others (coercion and manipulation), it is important to note that the extent to which a person's will is distorted and controlled should be evaluated relative to her own non-distorted and non-controlled state. Feinberg is very clear that voluntary choices need not be reasonable by any general criteria, but may be "eccentric" and "imprudent" (1986: 111). Donald VanDeVeer similarly argues that paternalism towards a person is justified when she would have consented to it if her normal capacities for deliberation and choice were not impaired, which, he explains, should be understood in an "individualized" way, not as a general standard of rationality (1986: 75-85). This means that the fact that children are in general more spontaneous, more emotional, and less rational, does not make interference with them soft rather than hard. The relevant question, for adults as well as children, is whether a person's choice is genuinely hers.

\section{For the good of a child}

Paternalism is almost universally taken to involve some sort of benefit for the person or persons interfered with, whether intended or actual or both. The benefit may be of any sort - material or moral, in terms of outcomes or opportunities. Since this is sometimes confused in the debate, it should be emphasized that the paternalist need not be imposing a foreign value on the paternalized and need not believe in any sort of perfectionist or objective values. It is paternalism if I force you to do what will maximize your preference-satisfaction or subjective wellbeing over time, or even if I force you to do what you think is best for yourself at the time, but that you do not do, perhaps because you seek your own detriment, or because you think other things than your own interests are more important, or simply because you do not have the will-power to do what you think best. However, that an interference is in accordance with a person's own view of her good arguably makes it a more justified case of paternalism.

Unlike with the interference component and the will component, there is no controversy around the fact that we can act for the good of a child. What may be controversial in the case of children is what exactly their good consist in. Childhood has sometimes been considered a mere preparation for adulthood. The more modern and to my mind correct view is that a child has two types of interests - the good for her now, as a child, and the good of her future adult self, as a more fully autonomous person with quite different interests (e.g. Archard 2015: chapter 3). Though it may seem obvious, the fact that a good childhood is intrinsically valuable is relatively new in mainstream political philosophy (Macleod 2010; Brennan 2014).

I will not discuss the extent to which the goods of childhood are in general distinct from the goods of adulthood (on this see Gheaus 2015). Given that there is something that is good for a child as a child and something else that is good for her as a future adult, paternalism towards her can be directed either at the former or at the latter, or both. For any individual young child, 
what is good for her at the moment and in her immediate future may have no correlation with what is good for her adult future self. Robert Noggle emphasizes that children typically [p. 130] cannot even comprehend what they will value as adults, or middle-aged persons (Noggle 2002). It may even be proposed that, morally speaking, the child and the adult are two quite different people, partly because of the differences in interests and the lack of anticipation of future interests, but also because of differences in personality, ability and social context. However, the differences between children and adults should not be exaggerated. As adults we also develop over time and typically have quite different interests in different periods of our lives. Indeed, it could be argued that many 25 -year-olds cannot even comprehend what they will value in their 60 s or 80 s. It may even be proposed that, morally speaking, the 25-yearold and her later 80-yearold successor are different people (which is one reason for why there are statutes of limitations in the criminal law).

To the extent that a person's future values and preferences are quite different from her current ones, it may be suggested that we should to some extent respect the former and not only the latter. In the case of children, it may be suggested that we should interfere with them for their own good in order to respect their future adult self. David Archard notes that this idea is an instance of subsequent consent, and so potentially self-justifying: the interference may cause a child to develop into an adult of the sort that consents to the interference (Archard 2015: 72-75). This also means, Archard notes, that different treatments may create different adults, all of whom would retroactively sanction, or rather approve of, the way they were treated. However, if an interference is benign in terms of its influence on decision-making ability, it does not seem so problematic that it is only one among several that would all be subsequently approved. What seems more problematic is the very idea of deferring to a person's future preferences rather than her present one's. This idea seems to presume either that she is presently incompetent and so does not have a will, or that she is temporarily impaired and so that her choices are not genuine. Both of these possibilities were discussed above and rejected as general justifications for interfering with children.

Invoking a child's future adult self has some similarity with invoking her hypothetical, more informed and rational self. This is the sort of justification of paternalism that I attributed to Donald VanDeVeer in the previous section - hypothetical individualized consent. For someone who is normally quite competent to make choices, but who is temporarily impaired, or even just in new and unexpected circumstances, it makes sense to consider what she would have wanted if she was more informed and more rational, making inferences from her statements and choices when at full or normal capacity. For someone who has never been very competent, however, there may be no unimpaired state from which to extrapolate such hypothetical consent. This seems especially problematic for children, who are typically at their hitherto maximal capacity and competence.

Another and arguably better way to acknowledge a person's future self is to cherish and encourage her particular nature so as to further her most promising development. It might perhaps be a form of respect to treat children, or people more generally, not just in line with their will or preference or life plan, but also in line with their personality and potential, providing them with opportunities that suit them and their development (Richards Early Online).

I acknowledged above that children are less prudent than adults and so there may often be stronger reasons to interfere with them because doing so yields greater benefits, relative to non- 
interference, than for adults. There is also the corresponding argument that interference is not as harmful to children as it is to adults. The proposals by Scarre and Richards that I rejected in the previous section as insufficient for undermining respect for the will of children may work in this context. For someone who is unable to make systematic plans for their own future, no such plans are jeopardized by interference. For someone who does not identify as a coherent, self-creating person, no such self-creation is disturbed by interference. Similarly, Roza Terlazzo [p. 131] has argued more explicitly that because settling on life projects is not as central to children's identities as it is for adults, interference with them is not as harmful to their self-respect and general wellbeing (Terlazzo 2015). If these authors are right, this may also mean that children do not have a view of their own good, if this means a considered judgment concerning one's interests over time. A more mundane reason for why it is less harmful to interfere with children than with adults is that children are used to being controlled by others and that it is less stigmatizing for them to be so controlled. All of these factors are more relevant for younger children and become gradually less relevant as children mature into adults. Even for young children, these plausible suggestions should not detract from the fact that many of them are oppressed and that such oppression is perpetuated by norms that normalize it by characterizing children as non-autonomous or lacking a proper will of their own.

\section{The child's future autonomy}

Autonomy is often singled out as an especially important future good for children, and so a strong justification for paternalism towards them. This aligns with a more general position that promotion and protection of autonomy provides a particularly strong justification for paternalism, since it is the very value that underpins resistance to paternalism (Mill 1859/1869; Dworkin 1972; Mitchell 2004). This general position may rest on a confusion between on the one hand respect for autonomy and on the other promotion and protection of autonomy. As Feinberg convincingly argues, to respect a person's autonomy includes respecting choices that diminish her own future liberty and autonomy (1986: 68-70). To compel a person to protect her future autonomy may be to impose a foreign value ranking on her, since she may value other things more (Arneson 1989: 435).

One could be consequentialist about this and hold that the reasons we have to respect autonomy are based entirely on the tendency of such respect to promote a person's interests, including her interests in being autonomous, now and in the future. Whether or not paternalism is justified would then depend on the costs and benefits of interference, in terms of how it affects these interests over time. Childhood is typically shorter than adult life, which means that restriction of autonomy in childhood resulting in increased autonomy as an adult will more likely be justified (unless an autonomous childhood is an independent and perhaps incomparable good).

There is also a more specific argument from autonomy that is sometimes invoked to justify paternalism towards children. It is based on the idea that each person should at some point in her life be fully autonomous, having the richest possible set of opportunities and the best possible ability to choose between these opportunities. This point in life is then assumed to coincide with a child's transformation into an adult, and so a (the) main purpose of childhood is to produce this 
optimally autonomous young adult, with, as it is often called, "an open future" (from Feinberg 1980/1994). It is not clear why there should be such a point in one's life or why it should coincide with becoming an adult. It seems likely that we could achieve a higher degree of autonomy, and so a more open future, at a somewhat later point, perhaps at age 30, when we are even more mature and informed, especially if our circumstances are designed to promote such development. Therefore, if we should respect the will of young adults, but not so much the will of children, this cannot be because the former have reached their full or highest autonomy.

\section{Conclusion}

I started this chapter by pointing to some difficult questions: to what extent may people harm or risk harm to themselves, or fail to promote their own interest? When should others interfere [p. 132] and what is the role a person's will and view of her good in this context? Throughout the chapter, I have discussed these questions in relation to the philosophical debate on paternalism and tried to draw out some lessons regarding paternalism towards children.

I have argued that children are rather like adults in many ways: they have a will, this will directs their actions, they typically act voluntarily, they can be interfered with, they have a future good that can be quite distinct from their current good, this future good includes their autonomy, and they have a personality and potential that can be nurtured. I have also recognized some ways in which children are different from many adults: their future good is generally, not just potentially, very different from their current good, they have not reached the peak of their autonomy, they are typically less prudent, they have less settled and systematic life plans, they are more used to interference and interference is not as stigmatizing for them. This last difference is of course connected to the fact that children are widely perceived as less competent and more in need of interference.

How do these conclusions help us answer the questions stated? They do so by helping us assess what is at stake in any one instance of benevolent interference with a child, whether in a single action or in the enactment or implementation of a policy. In particular, my conclusions undermine the position that children's lesser capacity for informed and rational choice means that paternalism towards them is either conceptually impossible or generally justified. At the same time, they explain why we often have stronger reasons for interference with children than with adults, and not as strong reasons against. ${ }^{2}$

\section{Notes}

1 In the sentence following on the quoted passage, Mill also rejects interference based on something being "right", which is generally taken as a rejection of moralism - interference motivated or justified either by the avoidance of the moral corruption of society, or by the avoidance of immoral behavior or moral fault, irrespective of its possible negative influence on the agent.

2 Thanks to Daniela Cutas, Anna Smajdor, Jurgen de Wispalaere, and especially Anca Gheaus for helpful comments. 


\section{References}

Archard, D. (1990) "Paternalism defined," Analysis 50(1): 36-42.

Archard, D. (2015) Children: Rights and Childhood, London: Routledge.

Arneson, R. (1989) "Paternalism, Utility and Fairness," Revue International de Philosophies 43: 409-437.

Arneson, R. (2015) "Nudge and Shove," Social Theory \& Practice 41: 668-91.

Aviram, A. (1991) "The Paternalistic Attitude Toward Children," Educational Theory 41: 199211.

Brennan, S. (2014) "Goods of Childhood and Children's Rights," In F. Baylis and C. McLeod (eds.) Family-Making: Contemporary Ethical Challenges, Oxford: Oxford University Press, pp. 29-46.

Casey, B.J., R.M. Jones, and T.A. Hare (2008) "The Adolescent Brain," Annals of the New York Academy of Sciences 1124: 111-126.

Dworkin, G. (1972) "Paternalism," Monist 56(1): 64-84.

Dworkin, G. (1983) "Paternalism: Some Second Thoughts," In R. Sartorius (ed) Paternalism, Minneapolis: University of Minnesota Press, pp. 105-111.

Feinberg, J. (1994) "The Child's Right to an Open Future," in his Freedom and Fulfillment: Philosophical Essays. Princeton: Princeton University Press. [originally published 1980]

Feinberg, J. (1986) Harm to Self, Oxford: Oxford University Press.

Frankel, S. (2012) Children, Morality and Society, Houndmills, Basingstoke: Palgrave Macmillian.

Gert, B. and C.M. Culver (1976) "Paternalistic Behavior," Philosophy and Public Affairs 6(1): 45-57.

Gheaus, A. (2015) "The 'Intrinsic Goods of Childhood' and the Just Society," In A. Bagattini and C. Macleod (eds) The Nature of Children's Well-Being, Springer Netherlands, pp. 35-52.

Gray, J. (1983) Mill On Liberty: A Defence, London: Routledge \& Kegan Paul. [p. 133]

Grill, K. (2015) "Respect for What? Choices, Actual Preferences and True Preferences," Social Theory and Practice 41(4): 692-715.

Hanna, J. (2015) "Libertarian Paternalism, Manipulation, and the Shaping of Preferences," Social Theory \& Practice 41(4): 618-43.

Macleod, C. (2010) "Primary Goods, Capabilities, and Children," in H. Brighouse and I. Roybens (eds) Measuring Justice: Primary Goods and Capabilities, Cambridge: Cambridge University Press, pp. 174-92.

de Marneffe, P. (2006) "Avoiding Paternalism," Philosophy and Public Affairs 34(1): 68-94.

Mill, J.S. (1859/1869) On liberty, London: Longman, Roberts \& Green.

Mitchell, G. (2004) "Libertarian Paternalism Is an Oxymoron," Northwestern University Law Review 99: 1245-78.

Mullin, A. (2014) "Children, Paternalism and the Development of Autonomy," Ethical Theory and Moral Practice 17(3): 413-26. 
Noggle, R. (2002) "Special Agents: Children's Autonomy and Parental Authority," In D. Archard and C. Macleod (eds) The Moral and Political Status of Children, Oxford: Oxford University Press, pp. 97-117.

Pope, T. (2004) "Counting the Dragon's Teeth and Claws: The Definition of Hard Paternalism," Georgia State University Law Review 20: 659-722.

Quong, J. (2010) Liberalism without Perfection, Oxford: Oxford University Press.

Richards, N. (2010) The Ethics of Parenthood, Oxford University Press.

Richards, N. (Early Online) "Raising a Child with Respect," Journal of Applied Philosophy, 10.1111/japp.12239.

Scarre, G. (1980) "Children and Paternalism," Philosophy 55: 117-24.

Schapiro, T. (1999) "What Is a Child?" Ethics 109: 715-38.

Scoccia, D. (2013) "The Right to Autonomy and the Justification of Hard Paternalism," In C. Coons and D. Weber (eds) Paternalism: Theory and Practice, Cambridge: Cambridge University Press, pp. 74-92.

Stevens, O. (1982) Children Talking Politics, Oxford: Martin Robertson \& Co.

Terlazzo, R. (2015) "Autonomy and Settling: Rehabilitating the Relationship between Autonomy and Paternalism," Utilitas 27(3): 303-325.

Thaler, R.H. and C.R. Sunstein (2003) "Libertarian Paternalism Is Not an Oxymoron," The University of Chicago Law Review 70: 1159-1202.

Thaler, R.H. and C.R. Sunstein (2008) Nudge: Improving Decisions about Health, Wealth, and Happiness, Yale University Press.

Tsai, G. (2014) "Rational Persuasion as Paternalism," Philosophy \& Public Affairs 42(1): 78112.

Van de Veer, D. (1986) Paternalistic Interference, Princeton: Princeton University Press. 